
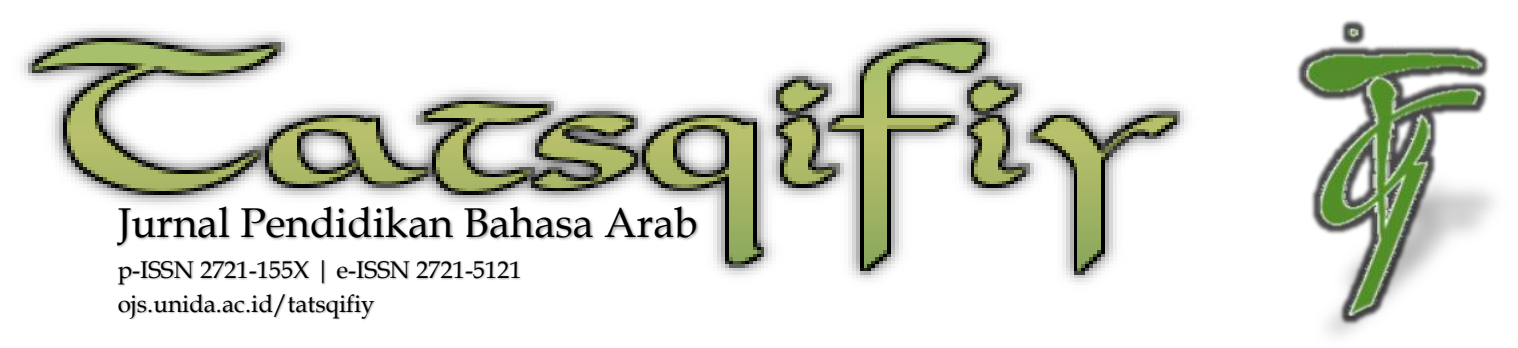

\title{
Hubungan Kemampuan Bahasa Arab Dengan Prestasi Menghafal Al-Qur'an Siswa Kelas XI MA Sirojul Athfal 2
}

\author{
Muhammad Farhan \\ Pendidikan Bahasa Arab, Fakultas Keguruan dan Ilmu Pendidikan \\ Universitas Djuanda \\ Jl. Tol Ciawi, Kotak pos 35 Bogor 1672 Telp. (0251) 8240773 Fax 8240985
}

Volume 2 Nomor 1

Januari 2021: 37-44

DOI: $10.30997 /$ tjpba.v2i1.3624

Article History

Submission: 01-10-2020

Revised: 03-11-2020

Accepted: 19-12-2020

Published: 25-01-2021

Kata Kunci:

Kemampuan Bahasa Arab, Prestasi, Menghafal Al-Qur'an.

Keywords:

Arabic Language Skills, Achievement, Memorize of Qur'an.

Korespondensi:

(Muhammad Farhan)

(Telp. 083893680946)

(muhammad6398729@gmail.com)
Abstrak: Al-Qur'an diturunkan dengan bahasa Arab, dengan bahasa inilah kita dapat membaca Al-Qur'an dan mempelajarinya. Berbicara mengenai bahasa Arab, tidak terlepas dari empat keterampilan: keterampilan membaca, keterampilan menulis, keterampilan menyimak, dan keterampilan berbicara. Pada masa sekarang di Indonesia, bahasa Arab bukan hanya dianggap sebagai bahasa asing, tetapi sudah menjadi salah satu pelajaran yang pokok di lembagalembaga sekolah. Adapun tujuan penelitian ini bermaksud mengetahui hubungan kemampuan bahasa Arab dengan prestasi menghafal Al-Qur'an. Kemampuan dalam bahasa Arab memiliki beberapa kata yang memiliki kemiripan makna, di antaranya kata al-Isti'dad, al-Qudroh dan al-Maharah. Adapun kemampuan yang dimaksud dalam penelitian ini adalah lebih spesifik pada al-Maharah dengan objek atau populasi yang diteliti bertempat di Madrasah Aliyyah Sirojul Athfal 2 pada seluruh kelas sebelas. Objek penelitian ini meliputi semua siswa kelas sebelas yang berjumlah 44 siswa sebagai fokus pemusatannya, sedangkan data diperoleh melalui metode wawancara dan metode dokumentasi yang berupa data-data sekunder. Adapun jenis penelitiannya menggunakan analisis korelasi antara variabel X \& variabel Y untuk diketahuinya hubungan diantara keduanya. Dan Hasil penelitian berdasarkan analisis data menghasilkan nilai hubungan sebesar 0,728 yang menunjukkan hubungan dalam interval yang kuat, maka hipotesis dapat diterima.

The relationship between ability of Arabic language with the achievement of memorizing the Qur'an eleventh grade students of Madrasah Aliyyah Sirojul Athfal 2 academic year 2019-2020 


\begin{abstract}
The Qur'an was lowered in Arabic and with this language we can read the Qur'an and learn it. When speaking Arabic, it is inseparable from four skills: reading skills, writing skills, listening skills, and speaking skills. At present Arabic in Indonesia is no longer considered a foreign language, but has become subject matter for primary school institutions. And as for purpose this study is to decide the connection between the ability of Arabic language to memorize the Qur'an. The object of testing in this research is Madrasah Aliyyah Sirojul Athfal 2 in all eleven classes. As for the total population in this study were all eleventh students totaling 44 students as the focus of concentration. The data collection in this study used interview and documentation methods in the form of secondary data. The type of this study uses correlation analysis between $X$ and $Y$ variables to determine the relationship between the two. And the results of research based on data analysis produce a relationship value of 0.728 which shows the relationship in a strong interval, so that hypothesis can be accepted.
\end{abstract}

\section{PENDAHULUAN}

Sebagai wahyu yang diturunkan Allah sebagai rahmat dan pedoman hidup, Al-Qur'san menjadi bagian yang utama bagi khususnya umat Muslim untuk mempelajari dan menjaganya. Bahkan diantara nama-nama Al-Qur'an, nama yang paling masyhur/ dikenal adalah nama Al-Qur'an (bacaan) dan AlKitab (tulisan). Penamaan Al-Qur'an dengan dua nama tersebut mengisyaratkan agar sepatutnya Al-Qur'an dipelihara baik dalam segi hafalan maupun tulisan dengan baik sebagai ibadah yang sangat agung dan mulia. Dengan cara pemeliharaan dari segi bacaan dan tulisan, maka Al-Qur'an akan tetap terjaga dengan kokoh. Maka demikian itu sebagai wujud janji Allah akan senantiasa terpeliharanya Al-Qur'an, seperti dalam firman-Nya,

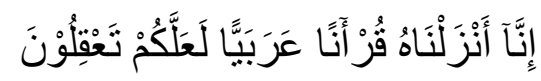

"Sesungguhnya Kami menurunkannya AlQur'an berupa Al-Qur'an dengan berbahasa Arab, supaya kamu mengerti." (QS. Yusuf: 2)

Al-Qur'an diturunkan melalui alLughah al-'Arabiyyah yang mana memiliki banyak keistimewaan dari bahasa-bahasa lainnya di dunia, bahkan saat diturunkannya Al-Qur'an, bahasa Arab telah mencapai kejayaannya, paling sempurna dari segi qawa'id, mufradat, uslub dan balaghah. Meski demikian, bahasa Arab dalam AlQur'an jauh lebih luhur kualitasnya dari pada bahasa Arab yang dipakai di masyarakat Arab saat itu, dan tidak ada dari mereka yang mampu membuat kalimat-kalimat yang serupa dengan keindahan bahasanya tersebut. 
Selain itu, ilmu gramatikal (qowa'id) dalam bahasa Arab sebenarnya berkembang dan didasari dari Al-Qur'an seperti Sharaf, Nahwu, dan Balaghah sehingga Al-Qur'an tidak dapat dipahami kecuali melalui bahasa Arab. Di antara begitu urgennya alLughah al-'Arabiyyah untuk memahami Al-Qur'an, perubahan kedudukan kata ditandai dengan i'rab (harakat akhir) dan ini tidak terdapat pada bahasa-bahasa yang lainnya selain bahasa Arab.

Dengan uraian di atas, maka sangat diperlukannya kemampuan bahasa Arab. Kata kemampuan (dalam bahasa Arab) memiliki beberapa lafaz, di antaranya adalah al-Isti' dad, al-Qudroh dan al-Maharah. Adapaun spesifik yang dikaji (penelitian ini) difokuskan pada al-Maharah. Dengan pentingnya memiliki al-Maharah al-'Arabiyyah tersebut, tentu akan menghasilkan manfaat besar bagi penghafal AlQur'an. Di antara beberapa urgensinya bagi seorang penghafal Al-Qur'an menurut Noza Aflisia (2016: 62-63) adalah sebaga berikut.

Pertama, keterampilan berbahasa Arab seseorang akan membantunya dalam menghafalkan AlQur'an, sebab ketika menghafal salah satu ayat, ketika itu akan ingat kisah ataupun tema ayat yang sedang dihafal. Walaupun lupa pada bunyi ayat, namun ketika ingat kisah yang terkandung, kemungkinan besar ia akan ingat juga lafaz-lafaz ayat tersebut. Kedua, dengan memiliki kemampuan bahasa Arab, akan membantu memahami maknamakna dari ayat Al-Qur'an yang dihafal sehingga akan mempermudah penghafalan. Ketiga, dapat menjaga dari kesalahan bacaannya. Artinya, ia dapat dengan mudah mengetahui dan mengingat harakat akhir sebuah kata dalam Al-Qur'an.

Di masa sekarang ini, perhatian lembaga-lembaga pendidikan terhadap tahfidz Al-Qur'an semakin meningkat. Salah satu yang menaruh perhatian tinggi pada siswa-siswanya dalam tahfidz Al-Qur'an adalah MA Sirojul Athfal 2 yang berada di Kecamatan Caringin, Kabupaten Bogor. MA Sirojul Athfal 2 merupakan Madrasah yang memiliki misi agar seluruh siswa/i nya menghafal Al-Qur'an sehingga memiliki hafalan Al-Qur'an, yang diantaranya adalah adanya target minimal 30 juz bagi kelas XI, dan di tahun 2019 Madrasah Aliyyah Sirojul Athfal 2 telah memasukkan Tahfidz 
(Menghafal Al-Qur'an) pada intra pelajarannya sehingga mulai tahun 2019 telah ada mata pelajaran Tahfidz untuk kelas 10, 11 dan kelas 12 nya.

Akan tetapi, dalam kegiatan belajar tahfidz di MA Sirojul Athfal 2 tersebut yang termasuk di dalamnya kegiatan menyetorkan hafalan Al-Qur'an, masih terdapat sebagian siswa yang belum mencapai target hafalannya, belum baik dalam kelancaran membaca Al-Qur'an dan masih kesulitan dalam menghafalkannya. Dengan permasalahan tersebut, dipikir perlu untuk mencari solusi alternatif yang dapat membantu mengatasi hal tersebut, dan penulis berpikir dan mengasumsikan agar lebih ditingkatkan dalam kegiatan belajar bahasa 'Arab yang dapat meningkatkan prestasi menghafal Al-Qur'an siswa.

Berdasarkan uraian di atas, maka penulis terinspirasi untuk melakukan penelitian guna mengetahui apakah ada hubungan antara al-Maharah bahasa Arab dengan prestasi menghafal AlQur'an pada siswa kelas 11 Madrasah Aliyyah Sirojul Athfal 2, yang diasumsikan bahwa kemampuan (alMaharah) bahasa Arab berkaitan erat dengan nilai hafalan Al-Qur'an. Yang artinya, karena Al-Qur'an adalah bahasa Arab, maka kemampuan berbahasa Arab dapat meningkatkan prestasi menghafal Al-Qur'an.

\section{METODE}

Dalam penelitian ini, pendekatan kuantitatif penulis pilih sebagai desain penelitian. Tujuan penelitiannya untuk mengetahui apakah ada hubungan kemampuan (al-Maharah) bahasa Arab sebagai variabel bebas $(X)$ dengan prestasi menghafal Al-Qur'an variabel terikat (Y). Penelitian kuantitatif (Quantitative Research) adalah penelitian yang bersifat induktif dan juga objektif, di mana data yang akan dihasilkan akan berupa angka-angka/ score, nilai atau beberapa pernyataan yang dinilai, dan dianalisis melalui analisis statistik. (Hemawan, 2019, hal. 16).

Penelitian ini termasuk jenis penelitian korelasional, dan sebagai populasinya adalah seluruh siswa kelas 11 MA Sirojul Athfal 2 dengan teknik pengumpulan data berupa data-data sekunder dari nilai-nilai kemampuan bahasa Arab serta nilai-nilai tahfidz AlQur'an siswa, serta menggunakan metode wawancara dan dokumentasi sebagai data-data pendukung yang diperlukan. Dengan demikian, peneliti 
menggunakan instrumen wawancara dan dokumentasi berupa nilai alMaharah bahasa Arab dan menghafal AlQur'an siswa kelas 11 MA Sirojul Athfal 2.

Setelah data-data yang diperlukan diperoleh, maka dilakukan analisis data dengan tiga tahapan umum, yaitu analisis deskriptif, uji prasyarat analisis berupa uji normalitas dan uji linearitas, dan terakhir adalah melakukan analisis data. Analisis data-data yang digunakan dalam penelitian ini yaitu dengan analisis korelasi, yaitu untuk mengetahui hubungan/ korelasi antara 2 variabel disertai tingkat kekuatan hubungannya.

Analisis korelasi dalam penelitian ini yaitu dengan metode Pearson atau sering disebut Pearson Product Moment. Uji Koefisien Korelasi Pearson adalah uji statistik untuk menguji kedua variabel yang memiliki data rasio ataupun data yang berisi angka-angka riil yaitu data sesungguhnya yang bersumber langsung dari angka asli. Dengan analisis korelasi Pearson ini, akan diperoleh koefisien korelasi antara kedua variabel dengan tingkat hubungannya.

\section{HASIL \& PEMBAHASAN}

Dari seluruh responden penelitian, diperoleh skor variabel $X$ dan variabel $Y$ dan kemudian peneliti melakukan analisis deskriptif pada masing-masing variabel, untuk mengetahui mean, in, max standar deviasi dan sebagainya. Hasil analisis deskriptif digambarkan pada tabel 1 berikut.

Tabel 1 Distribusi Frekuensi Skor Kemampuan Bahasa Arab Siswa

\begin{tabular}{cccccc}
\hline $\begin{array}{c}\text { Kelas } \\
\text { Interval }\end{array}$ & $\mathcal{F}$ & $\boldsymbol{X}_{\mathbf{1}}$ & $\mathcal{F} . \boldsymbol{X}_{\mathbf{1}}$ & $\boldsymbol{X}_{\mathbf{1}}$ & $\mathcal{F}_{\boldsymbol{i}}\left(\boldsymbol{X}_{\mathbf{1}}\right.$ \\
\hline $59-65$ & 1 & 62 & 62 & -16 & 256 \\
\hline $66-72$ & 8 & 69 & 552 & -9 & 648 \\
\hline $73-79$ & 18 & 76 & 1368 & -2 & 72 \\
\hline $80-86$ & 9 & 83 & 747 & 10 & 900 \\
\hline $87-93$ & 5 & 90 & 450 & 11 & 605 \\
\hline $94-100$ & 3 & 97 & 291 & 18 & 972 \\
\hline & 44 & & 3470 & & $\mathbf{3 4 5 3}$ \\
\hline & & & & &
\end{tabular}

Tabel 2 Distribusi Frekuensi Skor Prestasi

\begin{tabular}{|c|c|c|c|c|c|}
\hline $\begin{array}{c}\text { Kelas } \\
\text { Interval }\end{array}$ & $\mathcal{F}$ & $X_{1}$ & $\mathcal{F} . X_{1}$ & $\begin{array}{l}X_{1} \\
-\bar{x}\end{array}$ & $\begin{array}{l}\mathcal{F}_{i}\left(X_{1}\right. \\
-\bar{X})^{2}\end{array}$ \\
\hline $65-70$ & 13 & 67,5 & 877,5 & -9 & 1053 \\
\hline $71-76$ & 18 & 73,5 & 1323 & -3 & 162 \\
\hline $77-82$ & 2 & 79,5 & 159 & 3 & 18 \\
\hline $83-88$ & 3 & 85,5 & 256,5 & 9 & 243 \\
\hline $89-94$ & 4 & 91,5 & 366 & 15 & 900 \\
\hline $95-100$ & 4 & 97,5 & 390 & 21 & 1764 \\
\hline & 44 & & 3372 & & 4140 \\
\hline
\end{tabular}


Hubungan Kemampuan Bahasa Arab dengan Prestasi ...

Berdasarkan tabel 3 dan 4 di atas, frekuensi variabel dapat digambarkan dengan diagram berikut ini.

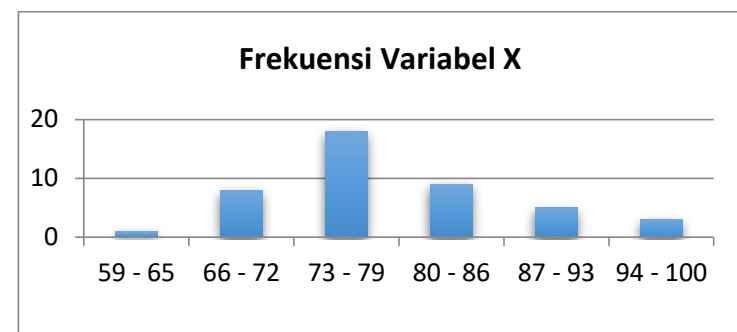

Dari diagram di atas, kita ketahui bahwa variabel kemampuan (alMaharah) bahasa Arab siswa paling banyak terdapat pada interval 73-79 dengan frekuensi 18 siswa, dan paling sedikit data terdapat pada interval 59-65 dengan frekuensi 1 siswa.

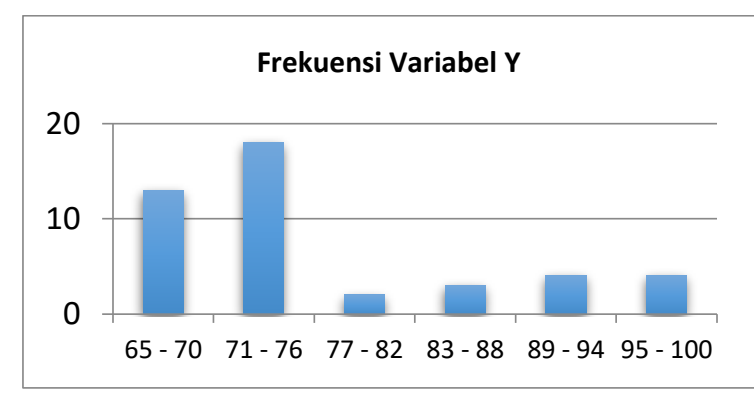

Dari diagram di atas, diketahui bahwa data variabel al-Maharah bahasa Arab siswa paling banyak terletak pada kelas interval 71-76 dengan frekuensi 18 siswa, dan paling sedikit data terdapat di kelas interval 77-82 dengan frekuensi 2 siswa.

Kemudian dilakukan pengujian prasyarat data yaitu uji normalitas dan hasilnya diperoleh bahwa variabel kemampuan/al-Maharah bahasa arab
(X) memperoleh nilai signifikansi 0.072 $>0.05$ dan pada variabel prestasi menghafal Al-Qur'an (Y) memperoleh nilai signifikansi $0.080>0.05$, sehingga bisa disimpulkan bahwa seluruh data pada penelitian ini adalah data yang distribusinya normal.

Kemudian selanjutnya adalah uji linearitas dan dari uji ini diperoleh nilai signifikansinya sebesar $0.778>0.05$ maka berdasarkan hasil tersebut diperoleh bahwa terdapat hubungan linear signifikan antara al-Maharah bahasa arab $(X)$ dan prestasi menghafal Al-Qur'an (Y).

Setelah diketahui data normal dan linear, selanjutnya dilakukan analisis korelasi dengan metode pearson. Untuk mengetahui terdapat hubungan atau tidak bisa kita lihat dari nilai signifikansi dan seberapa kuat hubungan tersebut bisa kita lihat dari nilai koefisien korelasi atau r. Kisaran nilai 1 sampai -1 nilai korelasi, semakin mendekati 1 atau -1 menunjukkan hubungan antara kedua variabel semakin kuat, dan sebaliknya bila mendekati 0 artinya hubungan antara kedua variabel lemah. Nilai yang positif menunjukkan adanya hubungan yang searah ( $X \& Y$ sama-sama naik) dan nilai 
negatif menunjukkan hubungan yang terbalik. Kategori korelasi dapat dibagi sesuai dengan tabel berikut :

Tabel 3 Pedoman Interpretasi Koefisien Korelasi

\begin{tabular}{cl}
\hline Interval Koefisien & Tingkat Hubungan \\
\hline $0,00-0,199$ & Sangat Rendah \\
\hline $0,20-0,399$ & Rendah \\
\hline $0,40-0,599$ & Sedang \\
\hline $0,60-0,799$ & Kuat \\
\hline $0,80-1,000$ & Sangat Kuat \\
\hline
\end{tabular}

Sumber: Sugiyono, 2012

Jika melihat nilai signifikansi, kedua variabel yang diuji dikatakan memiliki hubungan bila nilai signifikansinya $<0.05$ dan tidak terdapat hubungan apabila nilai signifikansi $>0.05$.

Hasil uji korelasi diperoleh signifikansinya sebesar $0.000<0,05$ sehingga dapat disimpulkan bahwa terdapat hubungan signifikan antara kemampuan (al-Maharah) bahasa arab (X) dan prestasi menghafal Al-Qur'an (Y) dengan nilai korelasi sebesar 0.728 yang dapat dikategorikan dalam hubungan dengan tingkat yang kuat. Dengan demikian maka dapat diambil sebuah kesimpulan bahwa semakin tingginya kemampuan (al-Maharah) bahasa arab maka semakin tinggi pula prestasi menghafal Al-Qur'an.

\section{SIMPULAN}

Berdasarkan uraian data yang telah dibahas di depan, hasil pengolahan uji signifikansi diperoleh nilai signifikansinya adalah $0.000<0,05$ sehingga dapat disimpulkan bahwa terdapat suatu hubungan signifikan antara kemampuan (Al-Maharah) bahasa Arab dengan prestasi menghafal AlQur'an siswa. Adapun korelasi pada hubungan kemampuan (al-Maharah) bahasa Arab dengan prestasi menghafal Al-Qur'an siswa diperoleh nilai korelasi sebesar 0,728 yang dapat dikategorikan dalam hubungan dengan tingkat yang kuat.

\section{DAFTAR PUSTAKA}

Aflisia, N. (2016). Urgensi Bhs. Arab bagi Hafidz Al-Qur'an. Jurnal STAIN Curup, 62-63.

Ainin, M. (2016). Metodologi Penelitian Bahasa Arab. Malang: CV. Bintang Sejahtera.

As-Sunaidi, S. b. (2008). Mudahnya Memahami Al-Qur'an. Jakarta: Pustaka Daarul Haq.

Bungin, B. (2005). Metodologi Penelitian Kuantitatif. Jakarta: KENCANA.

Devianty, R. (2017). Bahasa Sebagai Cermin Kebudayaan. Jurnal Tarbiyyah, 24, No.2.

Emzir. (2019). Metodologi Penelitian Pendidikan Kuantitatif dan Kualitatif. Depok: Rajawali Pers.

Fachrudin, Y. (2017). Pembinaan Tahfidz Al-Qur'an di Pesantren Tahfidzh Daarul Qur'an

Tangerang. Sekolah Tinggi Agama 
Islam Binamadani Tangerang, KOORDINAT Vol. XVI No.2.

Firmansyah, W. (2020). Pedoman Penulisan dan Penyusunan Skripsi FKIP UNIDA. Bogor: UNIDA PRESS.

Futuhy, F. (1990). Tadris al-Lughoh alArabiyyah fi al-Marhalah alIbtidaiyyah. Dar al-Andalus. Hadiansyah, S. (2018). Hubungan Kemampuan Bhs. Arab terhadap Prestasi Menghafal Al-Qur'an Santri kelas 3 MA. Skripsi. Fakultas Tarbiyyah dan Ilmu Keguruan, PAI, IAIN Salatiga, Salatiga. 15.

Hemawan, I. (2019). Metodologi Penelitian Pendidikan Kuantitatif, Kualitatif dan Mixed Methode. Kuningan: Hidayatul Quran Kuningan.

Izzan, A. (2015). Metodologi Pebelajaran Bahasa Arab. Bandung: Humaniora.

Kadir, A. (2020). Belajar Komunikasi Berbahasa Arab bagi Pemula dan Lansia. Yogyakarta: Deepublish. Munir. (2016). Perencanaan Sistem Pengajaran Bahasa Arab. Jakarta: Kencana.
Muradi, A. (2015). Pembelajaran Menulis Bahasa Arab Perspektif Komunikatif. 15.

Nasrudin, J. (2019). Metodologi Penelitian Pendidikan. Bandung: PT. Panca Terra Firma.

Rukajat, A. (2018). Pendekatan Penelitian Kuantitatif. Yogyakarta: Deepublish..

Rusydi, Ahmad (2004). Al-Maharaat alLughawiyyah. Darelfikri Arabi.

Singgih. (2010). Statistik Nonparametrik. Jakarta: PT. Alex Media Kompitudo.

Sudaryono. (2016). Metode Penelitian Pendidikan. Jakarta: KENCANA.

Sugiyono. (2012). Metodologi Penelitian Kuantitatif Kualitatif dan RED. Bandung: Alfabeta

Tanzeh, A. (2011). Metodologi Penelitian Praktis. Yogyakarta: Teras.

Wahid, W. A. (2013). Cara Cepat Menghafal Al-Qur'an. Jogjakarta: Diva Press.

Yulianti, L. (2018). Korelasi antara kemampuan Berbahasa Arab dengan Membaca Al-Qur'an.

Zubaidillah, H. (2018). Hubungan Kemampuan Bahasa Arab dengan Prestasi Hafalan Al-Qur'an. Jurnal STIQ Amuntai, STIQ Amuntai, Hulu Sungai Utara. 